\title{
Some effects of sulphur intake on molybdenum metabolism in sheep
}

\author{
BY N. D. GRACE* AND N. F. SUTTLE \\ Moredun Research Institute, Edinburgh $\mathrm{EH}_{\mathrm{I}} 7 \mathrm{7JH}$
}

(Received 25 January 1978 - Accepted I June 1978)

\begin{abstract}
I. To investigate the effects of sulphur intake on molybdenum metabolism in sheep, ewes were given intakes of 0.3 or $3.5 \mathrm{mg}$ Mo and $c .98, \mathrm{I} \cdot 33, \mathrm{I} \cdot 73$ or $3.23 \mathrm{~g} \mathrm{~S} / \mathrm{d}$ in a $2 \times 4$ factorial experiment with two replicates lasting $35 \mathrm{~d} .{ }^{\text {"a }}$ Mo with $0.1 \mathrm{mg}$ carrier Mo was infused intravenously for the last $14 \mathrm{~d}$ and, when ${ }^{98}$ Mo concentrations in urine and faeces had attained plateaux (days $11-14$ ), stable Mo and ${ }^{99}$ Mo balance trials were conducted; samples of blood and rumen contents were taken principally for studies of Mo distribution.

2. Increases in $\mathbf{S}$ intake caused the following changes in Mo metabolism; absorption decreased, urinary and faecal endogenous excretion decreased and retention increased; Mo concentrations in rumen contents decreased but the predominant association with the solid phase was unaffected; Mo concentrations in plasma decreased, but a higher proportion was associated with the protein fraction; Mo in protein-free plasma became apparently less ultrafiltrable at the glomerulus.

3. The pattern of response to $S$ for each factor was generally curvilinear, the first increment in $S$ intake having by far the greatest effect. The effect of $S$ was generally greatest at the higher Mo intake.

4. It is suggested that the manifold effects of $\mathbf{S}$ on Mo metabolism are related to a common interaction in the rumen leading to the formation of Mo-complexes, possibly thiomolybdates, which are poorly absorbed but even more poorly excreted.
\end{abstract}

Interest in the molybdenum metabolism of ruminants has centred on its role in interrelationships with copper and sulphur (Underwood, 197I) and been revived by suggestions that many facets of the complex interaction can be explained by thiomolybdate formation at gut and systemic sites (Suttle, 1974a; Dick et al. 1975; Mills et al. 1978). There is little fundamental knowledge about Mo metabolism per se but recent evidence that Mo is an essential nutrient for the ruminant (Anke et al. 1978) may alter the perspective. In one experiment with calves it was found that the absorbability of Mo was reduced during its passage through the rumen and that the primary site of absorption was the small intestine (Miller et al. 1972). Mo metabolism in sheep can, however, be markedly affected by changes in dietary composition (Bell I966), notably in the S constituent (Dick, I956). Dick (I956) concluded from a series of experiments that an increase in sulphate intake invariably reduced the retention of Mo but the specific contributions of changes in absorption and excretion to the interaction were not distinguished. The object of this paper is, therefore, to report the changes in Mo metabolism which occur when $S$ intake is varied for sheep at the relatively low Mo intakes commonly encountered under grazing conditions (cf. Whitehead, I966; Miltimore \& Mason, I97I): a preliminary report of this work has been published elsewhere (Grace \& Suttle, I978).

\section{MATERIALS AND METHODS}

Experimental design. Sixteen Scottish Blackface ewes, weighing $45-55 \mathrm{~kg}$ and equipped with rumen fistulas, were allocated at random in block design to a $2 \times 4$ factorial experiment with two replicates. Two intakes of $M o(0.3$ and $3.5 \mathrm{mg} / \mathrm{d})$ and four intakes of S $(0.98, \mathrm{I} \cdot 33$, $\mathrm{I} \cdot 73$ and $3.23 \mathrm{~g} / \mathrm{d}$ ) were arranged by infusing appropriate amounts of ammonium molybdate

* On study leave from Applied Biochemistry Division, D.S.I.R., Palmerston North, New Zealand. 
and sodium sulphate into the rumen. The lowest $S$ intake was just sufficient to meet the sheep's requirement for this element (National Research Council, 1957). The experiment lasted $35 \mathrm{~d}$.

Balance technique. Steps were taken to ensure that conditions in the rumen and in the whole animal were close to a state of equilibrium. The daily allowance of semi-purified diet (750 $\mathrm{g}$ dry matter (DM); Suttle \& Field, I968) was dispensed at hourly intervals by automatic feeders; it provided $6 \mathrm{mg} \mathrm{Cu}, 0.3 \mathrm{mg} \mathrm{Mo}$ and $0.98 \mathrm{~g} \mathrm{~S} / \mathrm{d}$. Additional Mo and S were delivered continuously into the rumen by means of a multi-channel peristaltic pump; this infusate provided most ( 1.81 ) of the deionized water intake, only $0.51 / \mathrm{d}$ being available for drinking. From $2 \mathrm{I} \mathrm{d},{ }^{98} \mathrm{Mo}$ as ammonium molybdate (Radiochemical Centre, Amersham, Bucks.) was infused continuously for $14 \mathrm{~d}$ via a catheter into the jugular vein. The infusate was prepared in sterile saline ( $9 \mathrm{~g}$ sodium chloride/l) and administered at a rate of $45 \mathrm{ml} / \mathrm{d}$ by syringe pumps. The dose on the first day was $0.2 \mathrm{mCi}$ and contained $0.1 \mathrm{mg}$ carrier $\mathrm{Mo}$ : this carrier Mo was added to the absorbed dietary Mo in calculating the partition of absorbed Mo (Fig. 3).

Faeces and urine were separated and the daily collections sampled for the determination of stable Mo and ${ }^{99} \mathrm{Mo}$ balances. Daily losses of ${ }^{99} \mathrm{Mo}$ were estimated throughout the isotope infusion (days 22-35) and those of stable Mo for days 30-35 only.

The following precautions were taken to avoid Mo contamination of samples: the metabolism crate had a framework of mild steel which was coated with polyurethane paint and enclosed, where practicable, with polyethylene sheeting; the grid through which faeces and urine passed had been coated with polyvinyl chloride (PVC) by a 'hot-dip' process and other exposed parts were covered with PVC tape; food and water containers and the separators for urine and faeces were largely of fibreglass, nylon or PVC construction.

Sampling and analytical methods. Blood samples for plasma $\mathrm{Mo},{ }^{99} \mathrm{Mo}$ and $\mathrm{SO}_{4}^{2-}$ determinations were taken into acid-washed tubes under vacuum from all animals at frequent intervals throughout the isotope infusion. In addition, plasma samples from two animals on three of the eight treatments $(0.98 \mathrm{~g} \mathrm{~S}$ and 0.4 or $3.6 \mathrm{mg} \mathrm{Mo} / \mathrm{d}, 3.23 \mathrm{~g} \mathrm{~S}$ and $3.6 \mathrm{mg} \mathrm{Mo} / \mathrm{d})$ were fractionated by ultracentrifugation. Equal volumes $(2.5 \mathrm{ml})$ of plasma and saline were mixed and centrifuged for $24 \mathrm{~h}$ at $\mathrm{I} 65000 \mathrm{~g}$ using a Spinco SW $50 \mathrm{~L}$ rotor (Smith \& Wright, I975); four I $\mathrm{ml}$ samples (fractions nos. I-4) were then successively removed from the top of the tube for Mo and ${ }^{99}$ Mo estimations: the final portion (fraction no. 5) contained most of the plasma protein (cf. Smith \& Wright, 1975) and was counted in situ.

Plasma $\mathrm{SO}_{4}^{2-}$ was determined in a trichloroacetic acid $(50 \mathrm{~g} / \mathrm{l})$ supernatant fraction by precipitating the $\mathrm{SO}_{4}^{2-}$ with ${ }^{133} \mathrm{BaCl}_{2}$ and comparing the radioactivity content of the washed ${ }^{133} \mathrm{BaSO}_{4}$ precipitate with similarly prepared standards(C. McMurray, personal communication).

Three samples of rumen contents were taken from each sheep on three occasions (days 30 , 32 and 35 ) via the rumen fistulas under vacuum (Suttle, I974b); one was mixed immediately with cadmium acetate (Gawthorne \& Nader, 1976), filtered through muslin and kept in gas-tight syringes for the determination of sulphide by the method of Bird \& Fountain (1970); another was centrifuged at $20000 \mathrm{~g}$ for $15 \mathrm{~min}$ to yield a clear supernatant fraction in which 'soluble' $\mathrm{Cu}$ and Mo concentrations were determined; the third sample was freeze-dried and its moisture and Mo contents determined. The contribution of Mo in the liquid phase to the total $\mathrm{Mo} / \mathrm{ml}$ rumen contents was calculated from the product of moisture content and 'soluble' Mo concentration.

Urine $(5 \mathrm{ml})$, freeze-dried faeces and diet samples $(0.5 \mathrm{~g})$ were dry-ashed at $500^{\circ}$ for $10 \mathrm{~h}$, dissolved in 10-20 ml warm 0. $25 \mathrm{M}$-hydrochloric acid and Mo was determined by the catalytic method of Bradfield \& Stickland (1975). Plasma and rumen contents were prepared for Mo analyses by wet acid digestion with a mixture of nitric and perchloric acids, care 


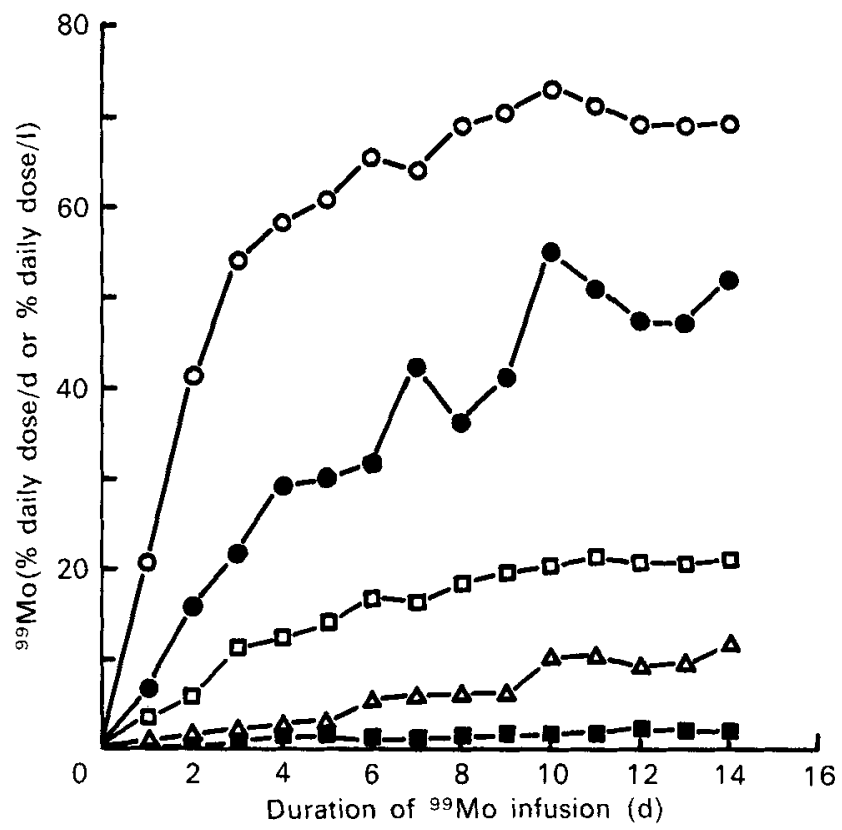

Fig. 1. Mean daily excretion (\% daily dose) of ${ }^{89} \mathrm{Mo}$ in urine $(O, \theta)$ and faeces $(\triangle)$ and concentration $(\%$ daily dose $/ 1)$ in plasma $(\square, \square)$ in ewes given ${ }^{90}$ Mo by continuous intravenous infusion. Only the most divergent responses to variations in sulphur and Mo intake are illustrated, i.e. urine ${ }^{99} \mathrm{Mo}$ averaged over all $\mathrm{S}$ intakes at $\mathrm{Mo}$ intakes $(\mathrm{mg} / \mathrm{d})$ of $0.3(0)$ or $3.5(\mathrm{O})$, plasma ${ }^{99} \mathrm{Mo}$ averaged over all Mo intakes at $S$ intakes $(\mathrm{g} / \mathrm{d})$ of $0.98(\square)$ or $3.23(\mathbf{m}) ;{ }^{90} \mathrm{Mo}$ in faeces showed little variation and a single over-all mean is given $(\Delta)$.

being taken to remove all $\mathrm{HClO}_{4}$ in taking the digest to dryness (Thompson \& Blanchflower, 197I) before extraction with $0.125 \mathrm{M}-\mathrm{HCl}$. S in the basal diet was determined by $\mathrm{X}$-ray fluorescence and $\mathrm{Cu}$ in rumen fluid and diets by atomic absorption spectrophotometry after wet acid digestion (Thompson \& Blanchflower, 1971). All glassware and plastic utensils were washed with $\mathrm{HNO}_{3}$ before use.

Counting procedures. Duplicate samples of approximately $10 \mathrm{~g}$ fresh faeces or rumen contents and 5-10 $\mathrm{ml}$ urine or plasma were counted. The gamma irradiations from ${ }^{89} \mathrm{Mo}$ and ${ }^{133} \mathrm{Ba}$ were counted in a well-type scintillation spectrophotometer fitted with a $250 \mathrm{~mm}$ sodium iodide crystal, using standards of appropriate geometry: standards for ${ }^{99} \mathrm{Mo}$ were prepared from the intravenous infusate. Counting problems relating to the production of the 'daughter' isotope ${ }^{99} \mathrm{Tc}$ were overcome by leaving the samples to equilibrate before counting (Bell et al. 1966).

Statistics and calculations. The faecal endogenous excretion of Mo and entry rate of Mo into the transport compartment were both estimated using the principle of isotope dilution, assuming that when equilibrium had been reached the specific activity (SA; \% daily dose $/ \mathrm{mg} \mathrm{Mo}$ ) of secreted and transported Mo was the same as that of urine. The formulae were as follows:

$$
\begin{aligned}
& \text { faecal endogenous loss }(\mathrm{mg} / \mathrm{d})=\frac{\text { faecal }{ }^{99} \mathrm{Mo}(\% \text {, daily dose } / \mathrm{d})}{\text { urine SA }}, \\
& \text { entry rate }(\mathrm{mg} / \mathrm{d}) \text { into transport compartment }=\frac{100}{\text { urine SA }} .
\end{aligned}
$$

Values for measurements which showed heterogeneity of variance (Bartlett's test) were subjected to logarithmic (base 10) transformation and those expressed as percentages to 
Arcsin transformations. Levels of significance of treatment effects were assessed by Tukey's test and the linear, quadratic and cubic components of the $S$ response curve were separated (Snedecor, 1956; Emersen, I968).

\section{RESULTS}

\section{Time interval taken to reach equilibrium}

The excretion of ${ }^{99} \mathrm{Mo}$ in urine and faeces and the concentration of ${ }^{99} \mathrm{Mo}$ in plasma increased steadily during the first 8-I I $\mathrm{d}$ of the isotope infusion and the results of the most divergent groups are given in Fig. I. Although the treatments affected the plateau levels attained, they did not markedly alter the time interval taken to reach equilibrium. Balance results from the last $4 \mathrm{~d}$ of the ${ }^{99} \mathrm{Mo}$ infusion were therefore used to establish the effects of the treatments on Mo metabolism.

\section{Mo balance trials}

The results from the stable and ${ }^{99} \mathrm{Mo}$ balance trials are presented in Table $\mathrm{I}$. The effect of increasing $S$ intakes was to increase the faecal excretion of Mo, to decrease the urinary excretion of Mo and to increase Mo retention: the effect on faecal Mo excretion was due to a decrease in Mo absorption rather than an increase in endogenous loss which actually decreased as $S$ intake increased (Fig. 2). The $S$ response curves were curvilinear, the first increment in $\mathrm{S}$ intake having by far the biggest effect on Mo metabolism. There was also an $\mathrm{S} \times$ Mo interaction in that the effect of the first $\mathrm{S}$ increment was most marked at the higher Mo intake. Tables $\mathrm{I}, 2$ and 3 show that this pattern of $S$ response was evident in most of the factors studied.

\section{Partition of absorbed Mo}

When the faecal endogenous and urinary excretions and the retentions of Mo were expressed as a proportion of absorbed Mo (Fig. 3) it became evident that $\mathrm{S}$ had altered the partition of absorbed Mo: the proportions excreted by both the faecal and urinary routes decreased and that retained increased as $S$ intake increased.

\section{Mo entry rates}

The results of the calculations of Mo entry rates are shown in Table I and Fig. 2. The general pattern of response to the $S$ and Mo supplements was similar to that for Mo absorption with the exception that as $S$ intakes increased, entry rates became progressively less than the estimates of true absorption.

\section{Rumen contents}

The main effects of $S$ and Mo intakes on the composition of rumen contents are shown in Table 2. Rumen $\mathrm{S}^{2-}$ concentrations reached a peak at an intake of $1 \cdot 73 \mathrm{~g} \mathrm{~S} / \mathrm{d}$, but were unaffected by Mo intake. Mo concentrations in the solid phase of the rumen contents decreased with the first increment in $S$ intake but further increments were without effect. Mo was associated predominantly with the solid phase of the rumen contents: the relative amount increased from 0.85 to 0.95 as Mo intake increased but was unaffected by $\mathrm{S}$ level. Soluble $\mathrm{Cu}$ concentrations were unaffected by the treatments, the over-all mean value being $0.13 \pm 0.05 \mathrm{mg} / \mathrm{l}$.

$$
\text { Plasma }{ }^{99} \mathrm{Mo} \text {, Mo and } \mathrm{SO}^{2-}
$$

The effects of $\mathrm{S}$ and Mo intakes on concentrations of Mo in plasma, and the relative concentrations of ${ }^{99}$ Mo to stable Mo (i.e. SA) in plasma and urine are given in Table 3. The major effects on plasma Mo and plasma SA were associated with the Mo supplement at the lowest intake of $S:$ it increased plasma Mo by $1 \cdot 4 \mathrm{mg} / 1$ and greatly decreased plasma $\mathrm{SA}$, but both effects largely disappeared when $\mathrm{S}$ intakes were increased. Both the SA of 


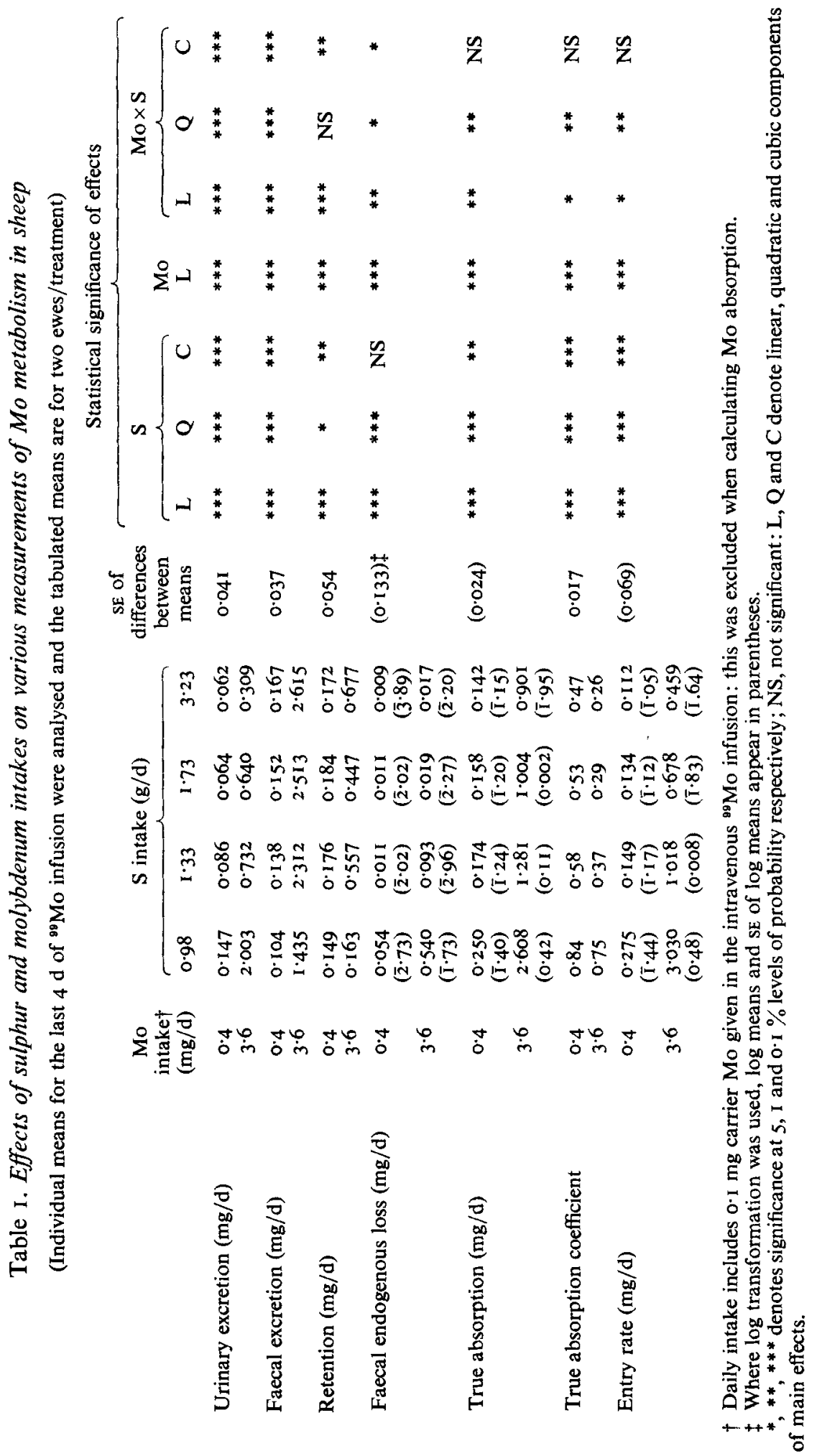




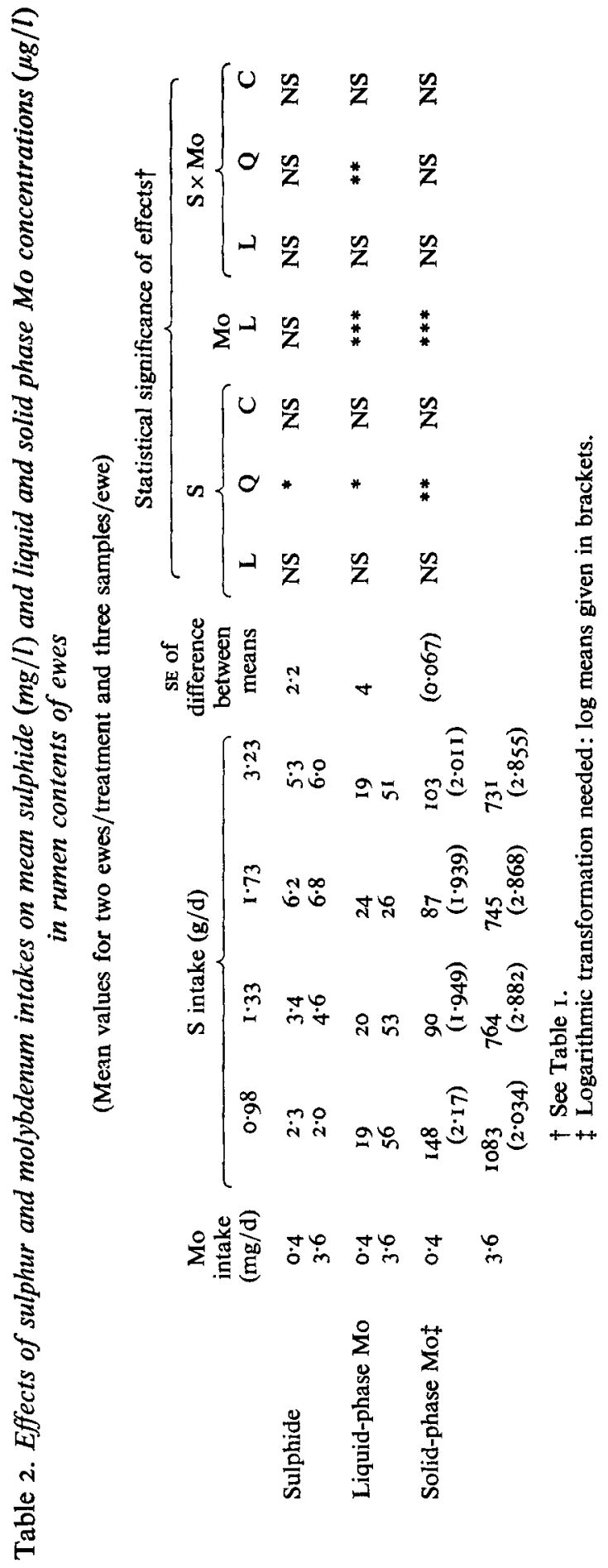




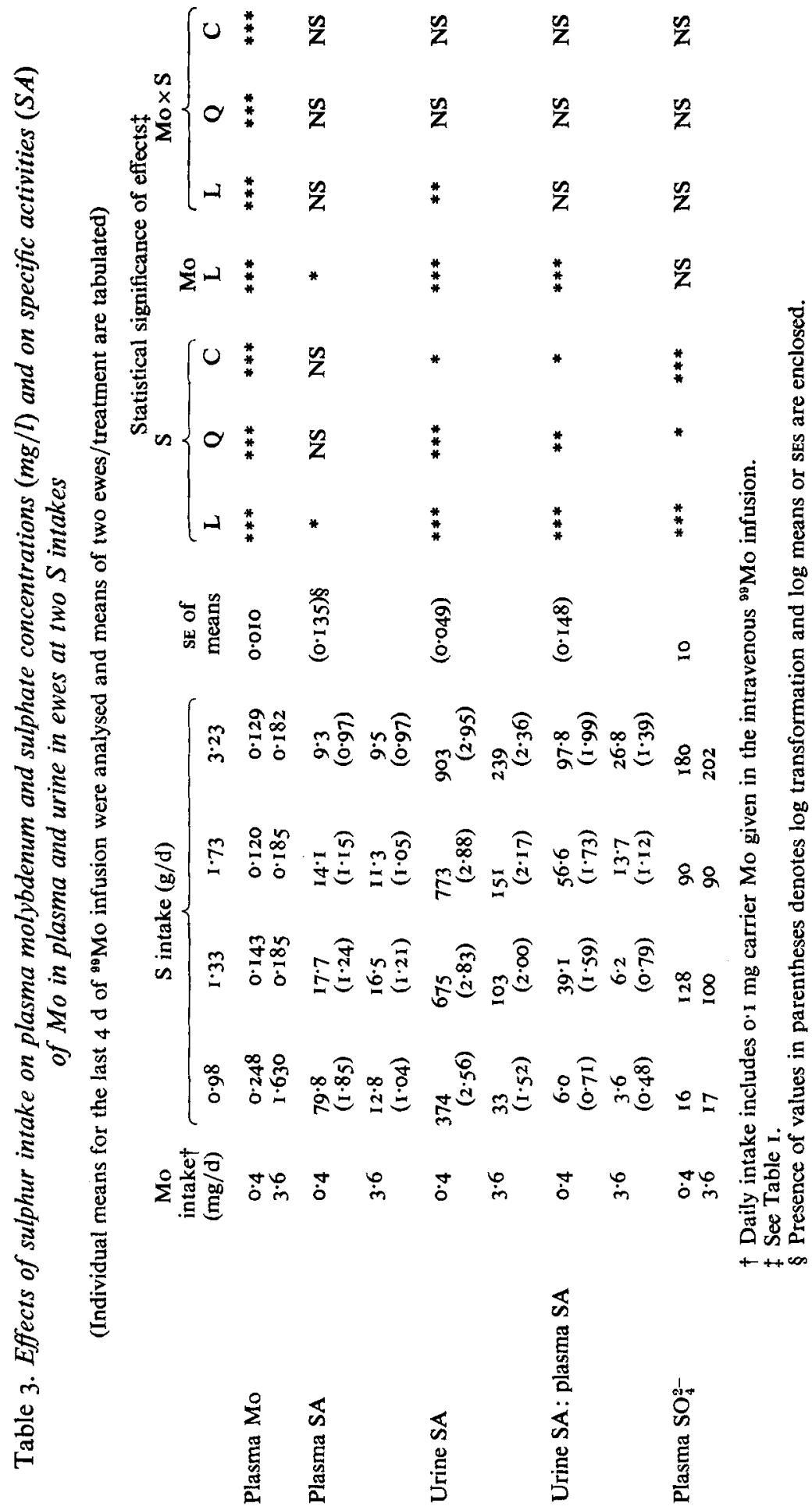




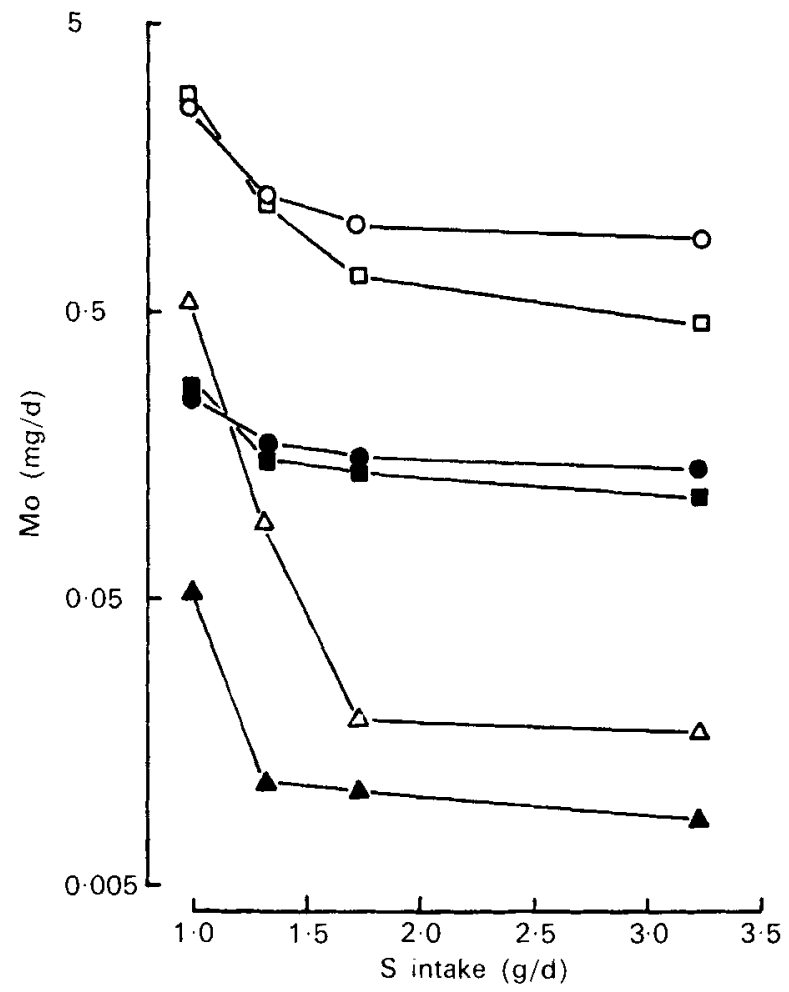

Fig. 2. Effects of sulphur intake $(\mathrm{g} / \mathrm{d})$ on the mean amount of molybdenum absorbed $(\mathrm{mg} / \mathrm{d})(\mathrm{O}$, ๑), excreted endogenously via the faeces $(\triangle, \Delta)$ or entering the transport compartment $(\square, \mathbf{m})$ in groups of two ewes on Mo intakes of $0.4(\mathbf{0}, \Delta, \boldsymbol{\nabla})$ or $3.6 \mathrm{mg} / \mathrm{d}(0, \Delta, \square)$.

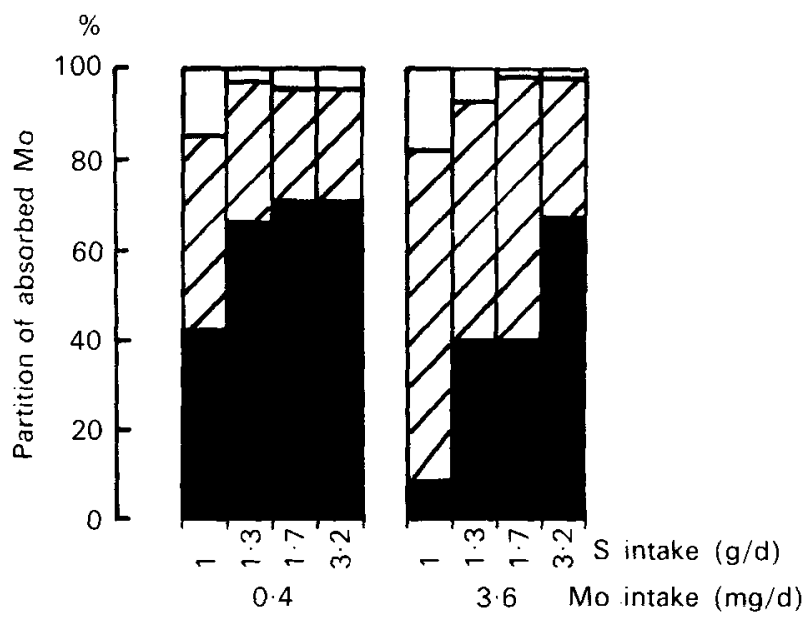

Fig. 3. Effect of sulphur ( $\mathrm{g} / \mathrm{d})$ and molybdenum $(\mathrm{mg} / \mathrm{d})$ intake on the mean proportion $(\%)$ of absorbed Mo excreted in urine $(\mathbb{Z})$ and endogenously in the faeces $(\square)$ or retained ( $\mathbf{D}$ ) by groups of two ewes. Carrier Mo, $0^{\circ} \mathrm{I} \mathrm{mg} / \mathrm{d}$, given with the intravenous infusion of ${ }^{90} \mathrm{Mo}$, was included as absorbed Mo. 


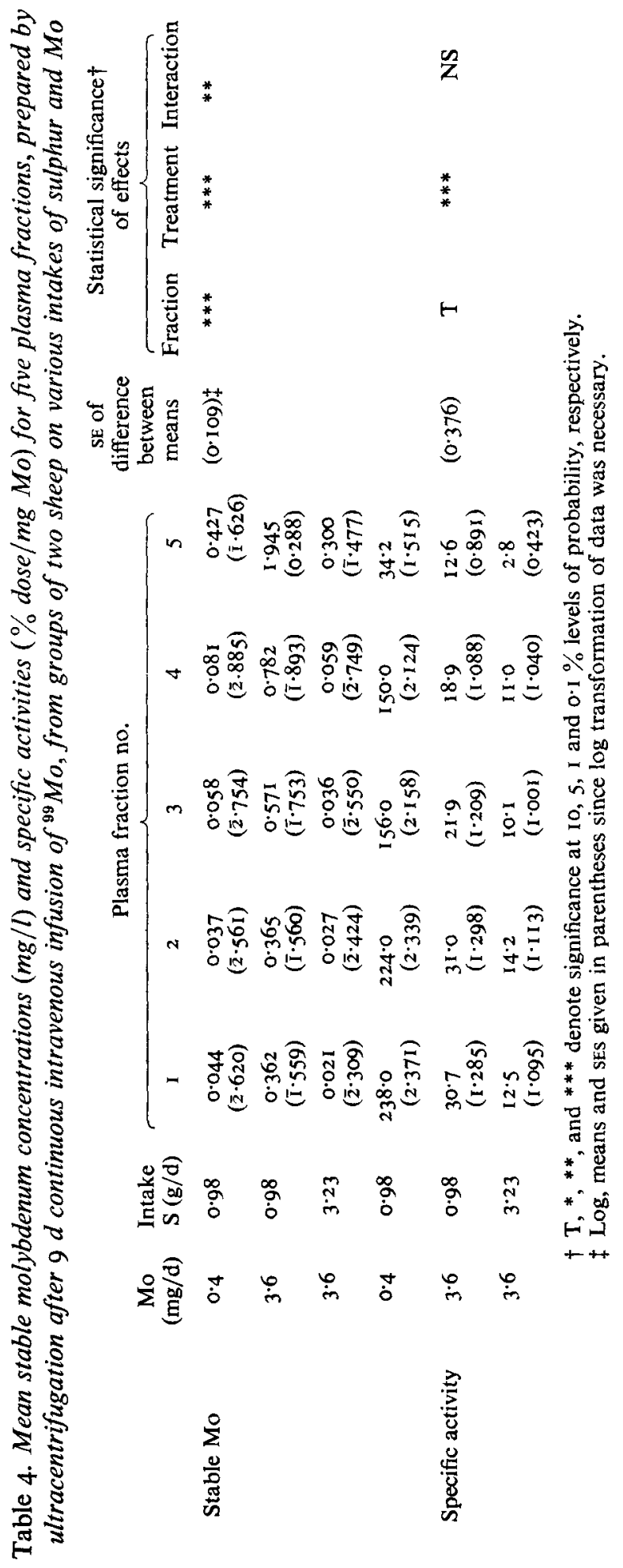


urine and urine:plasma SA were increased significantly by the first increment in $\mathrm{S}$ intake, whereas the Mo supplement had an opposite effect.

The results of the plasma fractionation are given in Table 4. For each of the three treatments studied, the protein-rich fraction no. 5 contained most of the stable Mo and had the lowest SA. However, with Mo intake high and S intake low, proportionately more Mo $(0.5 \mathrm{I} v .0 .32$ of total) was found in fractions nos. I -4 than occurred when intakes of both elements were high or low $(P<0.05)$. Low intakes of Mo and $\mathrm{S}$ were associated with high SA values in all fractions. A comparison of the SA values for plasma fractions with those for urine (Table 3 ) indicates that they were relatively close to unity for fractions nos. I and 2 from ewes on low intakes of $S$ but with high Mo and S intakes, urine SA:plasma SA for these fractions widened to $17 \cdot 8$.

Plasma $\mathrm{SO}_{4}^{2-}$ concentrations (Table 3 ) increased curvilinearly as $\mathrm{S}$ intake increased but were unaffected by Mo intake.

\section{DISCUSSION}

In estimating the faecal endogenous losses of Mo it was assumed that the SA of urine reflected that of the transport compartment from which faecal endogenous Mo was derived. Although such an assumption is commonly made in isotope studies (e.g. Bronner, 1964; Compère et al. 1965; Smith et al. 1968), it is uncommon to find large differences in SA between the urine and plasma fractions as we did on some treatments. If the Mo of low SA was more readily excreted by the faecal than by the urinary route, then the SA of faecal endogenous Mo would be closer to that of protein-free plasma than urine and truer estimates of faecal endogenous loss would be obtained by using the SA of the former. However, such computations produce similar estimates at the lowest $S$ intake and blatantly erroneous estimates, exceeding total faecal Mo excretion by a factor of 4 , at higher $\mathrm{S}$ intakes. We, therefore, conclude that the use of urine SA gives by far the most accurate estimations of faecal endogenous Mo and Mo absorption.

The presence of Mo fractions of low SA in the plasma, particularly at high Mo and S intakes, represents an important finding which helps to interpret other unexpected results from the experiment. A number of points can be made about the origin and properties of the low SA fraction. To have attained a low SA during the continuous intravenous infusion of ${ }^{9} \mathrm{Mo}$, the protein-free plasma must have acquired Mo-complexes from the gut where SAs were lowered by the entry of unlabelled dietary Mo. To have retained a low SA relative to that of the transport compartment, the complexes must have contained Mo which exchanged slowly, if at all, with Mo in that compartment. The formation in the gut of absorbable but poorly exchangeable Mo complexes would explain why Mo was absorbed at a rate which greatly exceeded its rate of entry into the transport compartment at high Mo and S intakes. The circulating Mo complexes are probably related to thiomolybdates formed in the rumen by an S-Mo interaction. Thiomolybdates $\left(\mathrm{MoO}_{x} . \mathrm{S}_{4-x} ;\right.$ Tridot \& Bernard, 1962$)$ have been produced by incubating rumen bacteria in $\mathrm{MoO}_{4}^{2-}$-rich media (Dick et al. 1975; Mills et al. I978). When administered via the alimentary tract, preformed thiomolybdates have produced changes in plasma $\mathrm{Cu}$ and Mo distribution (Bremner \& Young, I978) which are similar to those caused by dietary Mo and S supplements (Suttle \& Field, I968; Smith \& Wright, 1975; Bremner \& Young, 1978).

There was evidence in our experiment that the poorly exchangeable Mo complexes formed at high Mo and $\mathrm{S}$ intakes were poorly excreted by both the urinary and faecal routes. The low SA of protein-free plasma relative to urine can be explained by the failure of Mocomplexes to cross the glomerular membrane. The fall in Mo concentrations in rumen contents is consistent with a fall in secretion of Mo into the rumen, probably via the saliva, at high S intakes (Suttle \& Grace, 1978). The poorly excretable Mo complexes would 
be expected to have a relatively long biological half-life and the persistence of unlabelled complexes, formed before the ${ }^{99} \mathrm{Mo}$ infusion began, may have contributed to their ultimately low SA.

The formation of absorbable but poorly excretable thiomolybdate-type complexes at high Mo and $\mathrm{S}$ intakes may explain why Mo retention increased. The increase in Mo retention was most unexpected because earlier studies with both sheep (Dick, 1956; Scaife, 1956) and cattle (Cunningham \& Hogan, 1958; Cunningham et al. 1959) indicated that $\mathrm{S}$ supplements invariably reduced tissue Mo concentrations or Mo retention. The contrasting results are probably related to the use of very high Mo intakes and basal diets of low degradable $\mathrm{SO}_{4}^{2-}$ contept in the earlier studies, i.e. conditions which did not favour thiomolybdate formation. Under such conditions Scaife (1956) found no evidence of protein-bound Mo in the plasma of wethers and concluded that the high levels of readily dialysable Mo were present largely as inorganic $\mathrm{MoO}_{4}^{2-}$. The similar treatments used in other early studies may have caused Mo to accumulate in different forms from those encountered in our study. The decrease in Mo retention found by Dick (1956) and others when $\mathrm{S}$ intakes were increased could be explained by competitive inhibition of $\mathrm{MoO}_{4}^{2-}$ absorption from the intestine and renal tubule by $\mathrm{SO}_{4}^{2-}$ (Huisingh et al. 1973; Mason \& Cardin, 1977) under conditions which favoured the escape of $\mathrm{SO}_{4}^{2-}$ from the rumen through an Mo-induced inhibition of $\mathrm{SO}_{4}^{2-}$ degradation (Huisingh \& Matrone, I972; Gawthorne \& Nader, 1976).

Our experiments provide the first in vivo evidence that $\mathrm{S}$ impairs the absorption of Mo by ruminants; the effect was so pronounced that when Mo was given primarily as $\mathrm{MoO}_{4}^{2-}$ by intraruminal infusion, the efficiency of absorption was halved by the first increment in $S$ intake. Mo absorption was probably impaired as a result of an interaction with $S$ in the rumen because earlier work has shown that the absorption and urinary excretion of Mo is restored to high levels, despite a high $\mathrm{S}$ intake, when that organ is by-passed in giving Mo as an abomasal infusion (Suttle, 1975). One possibility is that some of the thiomolybdates formed in the rumen at high $S$ intakes remain insoluble and unabsorbable at sites of absorption further down the alimentary tract. Impairment of $\mathrm{MoO}_{4}^{2-}$ absorption by $\mathrm{SO}_{4}^{2-}$ is unlikely to have occurred since little $\mathrm{S}$ leaves the rumen as $\mathrm{SO}_{4}^{2-}$ at the low dietary Mo concentrations used in our study (Hume \& Bird, 1970).

Our discussion of the effects of S on Mo metabolism has been concentrated on the changes produced at the higher Mo intake where the effects were larger. The lesser effects at the lower Mo intake could be due to a variety of factors including the larger amounts of carrier relative to absorbed $\mathrm{Mo}$ and of inherent dietary relative to added inorganic Mo; homoeostatic adaptation in response to inadequate Mo absorption may also have occurred at the lower Mo intake.

We conclude that the Mo-S interaction in sheep is so complex that it is impossible either to define the normal Mo metabolism of sheep or to make valid generalizations about the way it is influenced by $S$ intake from the results of a single limited experiment. The narrow ranges of dietary Mo and S concentrations used in our experiment were, however, within a range commonly encountered in natural foodstuffs (Whitehead, I966; Miltimore \& Mason, I97I) and yet sufficiently wide to have produced in other studies a marked effect on the absorption of $\mathrm{Cu}$ (Suttle, 1975). We therefore suggest that the extent and implication of the S-Mo interaction and the thiomolybdates which it may generate under natural conditions merit further investigation.

The authors are indebted to Mr D. Pollock for preparing the diets, Mr J. N. Gibb and Mrs J. Williams for technical assistance, Mr B. Mitchell who performed the surgery, $\mathrm{Mr}$ M. McLauchlan for assistance with statistical analyses and $\mathrm{Dr} \mathrm{A}$. C. Field for his 
advice and encouragement. We are also grateful to Dr C. Evans of the Hill Farming Research Organisation, Edinburgh for $\mathrm{S}$ analyses.

\section{REFERENCES}

Anke, M., Grun, M., Partschefeld, M. \& Groppel, B. (1978). In Trace Element Metabolism in Man and Animals, p. 230 [M. Kirchgessner, editor]. Weihenstephan: Arbeitskreis für Tierernährungsforschung.

Bell, M. C., Sneed, N. N. \& Hall, R. F. (1966). Proc. 7th Int. Cong. Nutr. Hamburg 5, 765.

Bird, P. R. \& Fountain, R. D. (1970). Analyst, Lond. 95, 98.

Bradfield, E. G. \& Stickland, J. F. (I975). Analyst, Lond. roo, I.

Bremner, I. \& Young, B. W. (1978). Br. J. Nutr. 39, 325.

Bronner, F. (1964). In Mineral Metabolism, vol. 2, Part A, p. $4^{\mathrm{r}} 3$ [C. L. Comar and F. Bronner, editors]. New York: Academic Press.

Compère, R., Vanuytrecht, S. \& Fabry, J. (1965). Comp. Rend. Soc. Belg. Biol. 5, 1258.

Cunningham, I. J. \& Hogan, K. G. (1958). N.Z.Jl. agric. Res. I, 84 I.

Cunningham, I. J., Hogan, K. G. \& Lawson, B. M. (1959). N.Z. Jl. agric. Res. 2, I45.

Dick, A. T. (I956). Inorganic Nitrogen Metabolism, p. 445 [W. D. McElroy and B. Glass, editors]. Baltimore, Md: John Hopkins Press.

Dick, A. T., Dewey, D. W. \& Gawthorne, J. M. (1975). J. agric. Sci., Camb. 85, 567.

Emersen, P. L. (I968). Biometrics 24, 695.

Gawthorne, J. M. \& Nader, C. J. (I976). Br. J. Nutr. 35, It.

Grace, N.D. \& Suttle, N. F. (1978). In Trace Element Metabolism in Man and Animals, p. I59 [M. Kirchgessner, editor]. Weihenstephan: Arbeitskreis für Tierernährungsforschung.

Huisingh, J., Gomez, G. G. \& Matrone, G. (1973). Fedn Proc. Fedn Am. Socs exp. Biol. 32, I 92 I.

Huisingh, J. \& Matrone, G. (1972). Proc. Soc. exp. Biol. Med. 139, 518.

Hume, I. D. \& Bird, P. R. (1970). Aust. J. agric. Res. 21, 315.

Mason, J. \& Cardin, C. J. (1977). Res, vet. Sci. 22, 313.

Miller, J. K., Moss, B. R., Bell, M. C. \& Sneed, N. N. (1972). J. Anim. Sci. 34, 846.

Mills, C. F., Bremner, I., El Gallad, T. T., Dalgarno, A. C. \& Young, B. W. (I978). In Trace Element Metabolism in Men and Animals, p. I50 [M. Kirchgessner, editor]. Weihenstephan: Arbeitskreis für Tierernährungsforschung.

Miltimore, J. E. \& Mason, J. L. (I97I). Can. J. Anim. Sci. 5I, 193.

National Research Council (1957). Publ. nat. Res, Coun. Wash., no. 504.

Scaife, J. F. (1956). N.Z. Jl. Sci. Technol. 38 A, 293.

Smith, B. S. W., Field, A. C. \& Suttle, N. F. (I968). J. comp. Path. 78, 449.

Smith, B. S. W. \& Wright H. (1975). Clinica chim. Acta 62, 55.

Snedecor, G. W. (1956). In Statistical Methods Applied to Experiments in Agriculture and Biology, 5th ed., pp. 291, 329. Ames, Iowa: The Iowa State University Press.

Suttle, N. F. (1974a). Proc. Nutr. Soc. 33, 299.

Suttle, N. F. (1974b). Br. J. Nutr. 32, 559.

Suttle, N. F. (1975). In Trace Elements in Soil-Plant-Animal Systems, p. 27 I [D. J. D. Nicholas and A. R. Egan, editors]. New York: Academic Press.

Suttle, N. F. \& Field, A. C. (1968). J. comp. Path. 78, 351.

Suttle, N. F. \& Grace, N. D. (1978). Proc. Nutr. Soc. 37, 52 A.

Thompson, R. H. \& Blanchflower, W. J. (1971). Lab. Pract. $20,859$.

Tridot, G. \& Bernard, J. C. (1 962). Acta chim. hung. 34, 179.

Underwood, E. J. (1971). In Trace Elements in Human and Animal Nutrition, 4th ed., p. 123. New York: Academic Press.

Whitehead, D. C. (1966). Rep. Grassld Res. Inst., no. 4, p. 2 I. 